\title{
estar à escuta: música e docência na educação infantil
}

\author{
sandra regina simonis richter \\ universidade de santa cruz do sul, brasil \\ orcid id: http:/ / orcid.org/0000-0002-7902-5918 \\ dulcimarta lemos lino2 \\ universidade federal do rio grande do sul, brasil \\ orcid id: https:/ / orcid.org/0000-0002-1195-1683
}

resumo

O ensaio aproxima estudos em torno da dimensão poética da linguagem para abordar a relação entre docência na educação infantil e experiência de estar à escuta como modo estésico de coexistir no mundo. A aproximação entre filosofia, artes e educação infantil, desde o encontro entre e música e educação, sublinha que a escuta é o som do sentido e não o sentido do som a ser interpretado. A interlocução com o pensamento de Jean-Luc Nancy, ao permitir afirmar que o sentido sensível suscita o sentido sensato ou inteligível e o faz num movimento constante que não se completa ou finaliza produzindo uma significação ou uma informação, emerge como resistência filosófica ao privilégio do registro teórico fundado na primazia ocidental do modelo óptico. Estar à escuta implica a ressonância como o som do sentido, como profundidade primeira ou última do corpo. A música como jogo entre som e ruído, como produção poética de ordenação de sentidos sonoros provocados pela ressonância - como gesto de escutar a escuta, contribui para interrogar a educação de bebês e crianças pequenas a partir de um corpo que pode brincar com a sonoridade do mundo para viver a poética do barulhar como potência musical de jogar com sons e ruídos. $\mathrm{O}$ apetite sonoro das crianças as convocam a barulhar pela estesia de escutar o mundo na pluralidade da coexistência. O gesto de estar à escuta na docência com bebês e crianças pequenas aponta para ações educativas que consideram a experiência constituinte de ressonâncias e reverberações de sentidos imbricamos no som, um sentir se sentir (aisthesis), como partição e partilha das vozes, dos signos, dos gestos, das formas, do sentido sentido e do sentido sensato que nos situam sendo-uns-com-osoutros na coexistência mundana.

palavras chave: música; escuta; educação infantil; jean-luc nancy.

\section{estar a la escucha: música y docencia en la educación infantil}

resumen

El ensayo aproxima estudios acerca de la dimensión poética del lenguaje para abordar la relación entre docencia en la educación infantil y experiencia de estar a la escucha como modo sensible de coexistir en el mundo. La aproximación entre filosofía, artes y educación infantil, desde el encuentro entre música y educación, destaca que la escucha es el sonido del sentido y no el sentido del sonido a ser interpretado. La interlocución con el pensamiento de Jean-Luc Nancy, al permitir afirmar que el sentido sensible suscita el sentido sensato o inteligible y lo hace en un movimiento constante que no se completa o finaliza produciendo una significación o una información, emerge como resistencia

\footnotetext{
1 E-mail: s12richter@gmail.com

2 E-mail: dulcimartalino@gmail.com
} 
filosófica al privilegio del registro teórico fundado en la primacía occidental del modelo óptico. Estar a la escucha implica la resonancia como el sonido del sentido, como profundidad primera o última del cuerpo. La música como juego entre sonido y ruido, como producción poética de ordenación de los sentidos sonoros provocados por la resonancia -como gesto de escuchar la escucha, contribuye para interrogar la educación de bebés, niños y niñas pequeñas a partir de un cuerpo que puede jugar con la sonoridad del mundo para vivir la poética del hacer ruido como potencia musical del jugar con sonidos y ruidos. El apetito sonoro de los niños y niñas las llama hacer ruidos por la sensibilidad de escuchar el mundo en la pluralidad de la coexistencia. El gesto de estar a la escucha en la docencia con bebés, niños y niñas pequeñas apunta para acciones educativas que consideran la experiencia constituyente de resonancias y reverberaciones de sentidos solapados en el sonido, un sentir sentirse (aisthesis), como participación y intercambio de voces, de signos, de gestos de las formas, del sonido sentido y del sentido sensato que nos sitúan siendo-unos-con-los-otros en la coexistencia mundana.

palabras clave: música; escucha; educación infantil; jean-luc nancy.

\section{to be listening: music and teaching in early childhood education}

summary

The essay brings together studies around the poetic dimension of language in order to address the relationship between teaching young children and the listening experience as an aesthetic manner of coexisting in the world. This approximation between philosophy, arts and early childhood education begins with the meeting between music and education, and assumes that what we listen to is the sound that meaning makes, and not the meaning of a sound as an object of interpretation. Our text is inspired by Jean-Luc Nancy, who affirms that the sonorous invokes the sensible, and does so in a constant movement that never finishes producing a meaning. As such, it resists the privilege of the optical model in western theory. Nancy's Being in Listening associates resonance with the sound that the senses make deep in the body. Music as an interplay between sound and noise, as a poetic production, and a resonant organization of sensibility, encourages infants and young children to play with the sonorities of the world, and to live the poetics of noise as a form of empowerment. Children's appetite for the sonorous signifies a hunger for the deeply felt experience--the aesthesia-- of listening to the world in the plurality of coexistence. The gesture of listening with babies and young children is an educational one, which points to the world-constitutive experience of the resonances and reverberations of meaning that inhabit the sonorous. In listening with children, we are imbricated in sound, and experience ourselves as sharing in a sensible, polyphonic ground of voices, signs, gestures, forms and sensibilities, which act to situate us as beingwith each other in the world.

key words: music; listenin; early childhood education; jean-luc nancy. 
estar à escuta: música e docência na educação infantil

Neste ensaio aproximamos nossos estudos em torno da dimensão poética da linguagem para nos determos na relação entre docência na educação infantil e experiência de estar à escuta como modo estésico de coexistir no mundo. A intenção é destacar que o desafio da docência com bebês e crianças pequenas está em não somente transmitir informações ou visões sobre o mundo, mas também estar disponível para encantar o mundo com a potência sonora, mágicaz e fabuladora da linguagem.

Aqui, a intenção não é reafirmar uma "pedagogia da escuta" (RINALDI, 2012), a relevância educacional da sensibilidade pedagógica dos adultos ouvirem as crianças em suas necessidades, possibilidades e imprevisibilidades, mas destacar a experiência de ambos se entregarem à potência de estar à escuta. Para tanto, desde o encontro entre música e educação infantil, abordamos a escuta na docência com bebês e crianças pequenas como tensão, atenção e intenção pedagógica de considerar que o modo como escutamos dá existência às possibilidades de sentido (NANCY, 2007; 2013a). Dar existência à possibilidade de sentido significa não apenas ouvir aquilo que faça sentido $(\log o s)$ mas que ressoe no corpo sensível, fonte impalpável das sensações. Isto é, em todo sentido há uma ressonância4 - um fundo corporal - que simultaneamente nos coloca, nos enraíza e nos expõe ao mundo como constituinte da produção e da circulação das significações.

\footnotetext{
3 A palavra mágica é empregada a partir do verbo magicar que, conforme o Dicionário HOUAISS da Língua Portuguesa, significa "pensar insistentemente (em); cismar, ruminar; divagar com o pensamento; devanear, maginar".

4 Ressonância, para Nancy (2007, p. 82), é "ao mesmo tempo, a escuta do timbre e o timbre da escuta, se é lícito falar assim. É, ao mesmo tempo, a ressonância de um corpo sonoro para si mesmo e a da sonoridade de um corpo que escuta e que, ele mesmo, soa ao escutar". Cabe destacar que essa ressonância não é um dado imóvel e imutável, pois o timbre é dinâmico e, por consequência a escuta. "O timbre é a ressonância do som: ou seja, o som mesmo. Forma a consistência primeira do sentido sonoro como tal, sob a condição rítmica que o faz ressoar (mesmo um som monótono simplesmente sustentado é ritmado e timbrado)" (NANCY, 2007, p. 83).
} 
estar à escuta: música e docência na educação infantil

Nessa compreensão, a ação educativa com bebês e crianças pequenas na educação infantil ultrapassa a comunicação de significados pela intencionalidade pedagógica de estar em presença de como gesto produtor de sentidos com outros em uma temporalidade na qual a surpresa e o inesperado possam acontecer e tecer mundos. A presença sonora implica atenção ao outro, ao "ser todo ouvido", à disponibilidade ao gesto de escuta de si e dos outros. Essa disposição estésica ao presente sonoro promove encontros que dilatam o tempo e que, por ressoarem, se abrem e se ramificam em reverberações. As crianças, desde bem pequenas, antes de aprenderem a língua e a tudo nomear, adentram na complexidade dos segredos da convivência a partir dos vínculos sensíveis que o corpo estabelece com o mundo. Nessa compreensão, a ação educativa torna-se uma experiência de sentido na qual “o sensível suscita o inteligível e o faz num movimento constante que não se completa ou finaliza produzindo uma significação ou uma informação" (GHETTI, 2013, p. 149), antes emerge como uma presença que está no e é mundo em uma relação tão corpórea quanto incorpórea que afeta em proporções e intensidades distintas. Exige uma disponibilidade adulta à coexistência com as crianças no movimento vital do corpo ressoante como gesto de escuta que integra a relação de sentido.

Ao destacarmos a inseparabilidade entre corpo sensível, mundo e dimensão poética da linguagem aproximamos filosofia, artes e educação infantil para afirmar o encontro entre educação e música como experiência constituinte de ressonâncias e reverberações de sentidos imbricados no som. Essa aproximação permite apontar que algo acontece entre pensamento e som. Para abarcamos esse acontecimento, partimos de uma interlocução com Jean-Luc Nancy por sua instigante dilatação das fronteiras da filosofia ao situar a centralidade tanto da produção do sentido na singularidade plural5 das artes quanto da produção poética como eclosão e efetivação do real.

\footnotetext{
5 Em Nancy (2007; 2008; 2013a; 2014), as artes constituem os distintos nomes dados ao poético e seus relatos. O princípio heterogêneo da singularidade plural das artes é a sensualidade como sentir sentido e sentir senciente a partir da complexa relação que mantêm entre si os dois sentidos do sentido: sentido sensato ou inteligível e sentido sensivel, na qual não há subordinação de um pelo outro.
} 
Se para Nancy (2008, p. 43) é a sensualidade de tocar o mundo que promove a emergência do sentido inteligível das artes, para José Miguel Wisnik (1989, p. 30) "o jogo entre som e ruído constitui a música”. Assim, o encontro entre filosofia e música permite sublinhar que a escuta é o som do sentido e não o sentido do som a ser interpretado. Ao brincar com sons, isto é, "barulhar" (LINO, 2008) as crianças se entregam ao risco de ressoar sentidos na imprevisibilidade e indeterminação características do jogo. Sem fragmentação ou hierarquias, sonoro e musical coexistem na rede de singularidades da experimentação sonora de distintos modos de ser música.

A obra de Nancy aponta que o pensamento é antes de tudo sensível (CERF, 2012), evento de uma abertura "no rigor da errância, e na exposição deste serexposto a que se chama 'a existência'” (NANCY, 2011, p. 19), pois a ele interessa "a existência do sentido mais do que o sentido da existência" (NANCY, 2011, p. 21). Aqui, mesmo que a existência não tenha sentido, na acepção de uma determinação ou uma enunciação no âmbito das significações, "o sentido existe, ou ainda: a existência é ela mesma o sentido, é a significância absoluta (a significância do ser) por isso mesmo e nisso mesmo que ela existe" (NANCY, 2011, p. 21). Tal proposição o afasta de uma tradição filosófica pautada na ciência do ouvir - a do século $X X$ - e o conduz "à beira de outras escrituras (...) uma filosofia que seja apenas o estremecimento de um som" (CERF, 2012, p. 4) para reivindicar outra filosofia que se aproxime da escuta. Nas palavras do filósofo,

$$
\begin{aligned}
& \text { estar à escuta é sempre estar na borda do sentido, ou em um sentido de } \\
& \text { borda e de extremidade, como se o som não fosse de fato nada mais que } \\
& \text { essa borda, essa beira ou essa margem - ao menos o som musicalmente } \\
& \text { escutado, isto é, recolhido e escrutado nele mesmo, porém não como } \\
& \text { fenômeno acústico (ou não somente) mas como sentido ressonante, } \\
& \text { sentido cujo senso supõe-se encontrar na ressonância, e apenas nela se } \\
& \text { encontrar (NANCY, 2013a, p. 163). }
\end{aligned}
$$

É nessa particularidade de borda - e de abordagem da relação entre filosofia e música - que propomos considerar a "música e sua relação com o sentido (sensível e inteligível), como também sugerir que os modos como se escuta o som impregnariam a existência de possibilidades de sentido" (GHETTI, 2013, p. 150). Possibilidades que envolvem a ressonância como o som do sentido, como 
estar à escuta: música e docência na educação infantil

profundidade primeira ou última do corpo. Nessa compreensão, estar à escuta implica estar em tensão e na espreita de um sentir se sentir (aisthesis) a "si mesmo", um "estar em ou tendido para um acesso a si" (NANCY, 2013a, p. 165), uma escuta de si como possibilidade de dar-se à ressonância ou à escuta ao silêncio do sentido como resistência filosófica ao privilégio do registro teórico fundado na primazia ocidental do modelo óptico.

Resistir, na ação educativa com crianças, à concepção de escuta como habilidade ou aprendizagem de representacionalidades funcionais acústicas supõe enfrentar a presença das artes na educação tanto como criação ex-nihilo quanto como ensino fragmentado em áreas ou disciplinas e passar a considerar a potência do corpo estar à escuta, ou seja, de corpo em presença no mundo. Essa resistência é um convite à docência na educação infantil pensar a ação educativa a partir da existência das crianças - aqui e agora, em coexistência, e não a partir de prévias explicações sobre elas ou sobre "arte". Prévias concepções que não permitem considerar a potência lúdica de iniciar um gesto no mundo ao definirem uma ação já determinada por sua nomeação, ou seja, por prévias classificações.

Não se trata de reivindicar uma deliberada busca de clareza teórica, antes implica assumir o profundo incômodo que as coisas da arte provocam em seu encontro com a educação básica. Os fazeres como saberes encarnados, a imitação como repetição lúdica, o ficcional como experiência de pensamento imagético, a sensibilidade lúdica e lúcida de uma experiência de linguagem exigente e interpeladora, incomodam porque exigem ser partilhados. Ou seja, exigem dos adultos docentes a tarefa lúdica de imaginarem e serem brincantes das distintas dimensões de linguagem para provocarem a imaginação e desafiar o raciocínio brincante das crianças, para juntos realizarem a experiência de escuta e partilha de um mundo comum no qual ambos estão em relação temporal de alteridade linguageira.

Aqui, o gesto de escutar diz respeito ao sentido como abertura e possibilidade em contraposição ao gesto de ouvir como compreensão de sentidos prévios a partir de uma convenção ou predeterminação. Com Nancy (2007; 2013a) 
interrogamos o que estaria em jogo na escuta "quando alguém se esforça para captar ou para surpreender muito mais a sonoridade do que a mensagem?" (NANCY, 2013a, p. 162). O que consistiria estar à escuta na docência com bebês e crianças pequenas? A escuta seria ela mesmo sonora? Ou ainda, o que estaria em jogo na ação educativa quando adultos e crianças se lançam na experiência de estar à escuta da música na Educação Infantil?

\section{estar à escuta}

O verbo escutar vem do latim, auscultar, prestar ouvidos, ouvir com atenção, ouvir às escondidas, obedecer. Estar à escuta é relacionada à espionagem militar, à confidência, ao segredo roubado. Do mesmo modo indissociável, estar à escuta é estender a orelha, compreender, fazer sentido. Em toda cadeia de sentido há um escutar e no próprio escutar, uma escuta. Yoko Ono (MALBA, 2016) é provocativa ao instalar a "instrução":

Escuta tua própria respiração:
1) ao amanhecer
2) de manhã
3) a tarde
4) à noite
5) antes de amanhecer

O texto em letras pretas sobre uma grande parede branca, transcrito acima, faz parte de uma das peças compostas por Yoko Ono em sua exposição retrospectiva Dream Come True (MALBA, 2016). Quando adentramos o Museu de Arte Latino-Americana de Buenos Aires, o MALBA, nos deparamos com um número significativo de pessoas experimentando sua respiração. A mostra marca o pioneirismo de Yoko na arte conceitual quando a artista, nos anos 1960, rompe com as fronteiras tradicionais que dividem as distintas artes, criando outro modo de relação com os espectadores no museu. A artista espalha diferentes “instruções" pelo espaço, isto é, peças com breves mensagens poéticas, as quais convidam as pessoas a realizarem determinadas ações para sublinhar a dimensão lúdica da linguagem. Quando entramos no museu logo percebemos a noção 
estar à escuta: música e docência na educação infantil

eminentemente corpórea da proposta artística ao observamos o constante movimento do público que acolhe e participa de suas proposições.

Na instalação de Yoko Ono, a escuta é gesto, é movimento expressivo que emerge da ação de tocar o mundo e ser por ele tocado. Aqui, o mundo não é nem representação, nem ponto de vista e nem espaço sociocultural contingente e relativo, não é aquilo que eu penso, "mas aquilo que eu vivo; eu estou aberto ao mundo, comunico-me indubitavelmente com ele, mas não o possuo, ele é inesgotável" (MERLEAU-PONTY, 1999, p. 14). Há o mundo e o movimento expressivo organiza ele mesmo o corpo, pois o expresso não existe sem a expressão, ou nos termos de Nancy (2008, p. 31), “a arte não diz respeito ao 'mundo' entendido como exterioridade simples, meio ou natureza. Diz respeito ao ser no mundo em seu próprio surgimento". Nessa compreensão, a dimensão poética da linguagem faz o mundo se deslocar em mundos plurais, na qual "a pluralidade sensível e técnica das artes induz o sentido inteligível" (NANCY, 2008, p. 43), pois o mundo é o que em nós sentimos e que, contudo, precisamos apreender o sentido para significá-lo e compartilhá-lo.

Para explicitar nossa concepção de mundo sonoro, convidamos o leitor à memória de uma brincadeira de crianças conhecida como esconde-esconde. Nessa brincadeira alguém, de olhos fechados, conta até certo número enquanto os outros devem procurar um local secreto para se esconderem. O objetivo é esconder-se e não ser encontrado. $\mathrm{O}$ acontecimento ou mundo sonoro aqui considerado poderia se referir à memória de escuta alcançada enquanto permanecíamos no local secreto à espera de sermos encontrados. Nesse instante, todo o nosso corpo se transformava em ouvido! A força do som era sentida tanto no movimento quanto no silêncio. Então, o coração batia forte, os sons da paisagem sonora ressoavam com maior evidência (em muitos casos revelando sonoridades ouvidas pela primeira vez). O reservatório de silêncio inundava o encontro que parecia se estender na eternidade.

Na sensibilidade ou estesia de escutar-se escutando o mundo, o silêncio emerge não apenas como privação, mas sobretudo, nos termos de Nancy (2013a, p. 
172), como uma disposição de "se abrir à ressonância do ser ou ao ser como ressonância". Em outras palavras, em uma condição de silêncio na qual "escuta-se ressoar o próprio corpo, seu sopro, seu coração e toda a sua caverna repercussiva" (NANCY, 2013a, 172). Supõe acolher com Heller (2011, p. 20), que o silêncio "não é a ausência de uma presença, mas a presença de uma ausência: uma ausência que se faz ouvir, que faz diferença, que produz". Algo difícil de abarcarmos diante da tendência hegemônica do pensamento ocidental considerar, em sua incansável busca pelo "real objetivo" como identidade de uma representação, apenas o sentido da visão na relação com o inteligível. Porém, destaca Nancy (2007; 2013a), frequentemente esquecemos que na caverna de Platão (514a-517c), no livro VII de A república, não há apenas sombras, mas também o eco das vozes.

Em Nancy (2007; 2013a), é pela ressonância (pelo som do sentido e não pelo sentido do som) que o sonoro expõe sua singularidade em relação ao visual - ao registro óptico manifestado como inteligível pela relação teórica6 - como diferença intransponível, ainda que um não possa dispensar o outro. Ao distinguir a singularidade do sonoro (ressonância) com relação ao óptico (evidência), Nancy (2013a, p. 165) estabelece uma incidência particular do som afetar que não instala relação de reciprocidade no modo como ele faz sentido. Se a reciprocidade entre o visual e o conceitual é sempre apreendida como "forma", que implica a ordem visual,

o sonoro, ao contrário, arrebata a forma. Não a dissolve, antes a alarga, dá a ela uma amplitude, uma espessura e uma vibração ou ondulação cujo desenho nada mais faz que aproximar. O visual persiste ainda em seu desvanecer, o sonoro aparece e se desvanece mesmo em sua permanência (NANCY, 2013a, p. 160).

$\mathrm{Na}$ filosofia de Nancy $(2011 ; 2013 a)$ o verbo escutar guarda uma combinação de proposições que integram tanto o órgão sensorial (ouvido, orelha)

\footnotetext{
6 Conforme Bornheim (1988, p. 89), o verbo theoréin deriva de um nome: theoros, ser espectador e, assim, a teoria é "um ver concentrado e repetido, um ver que sabe ver, que inventa meios para ver cada vez melhor. E é nessa educação do olhar, a partir dela, que se institui toda a filosofia e as ciências do Ocidente". A partir do olhar atento, de Homero a Platão, é constituída uma decisiva história da visão vinculada ao ato inteligível ou lógico (logos) de compreensão. O olhar, como operação intelectual capaz de separar a sombra produzida pela tonalização da luz sobre as coisas, suas aparições, põe o mundo como representação ou conceito: aquele que contempla o que vê, ao mesmo tempo contempla e analisa.
} 
estar à escuta: música e docência na educação infantil

como a tensão, a intenção, a atenção. Essa combinação aponta que escutar é tanto estender a orelha quanto uma preocupação, uma curiosidade, uma inquietude. Se o que o mundo oferece são ruídos, não é instigante "ver a orelha desenhada por nosso ponto de interrogação? Ele traça a espera do corpo e o pavilhão desejoso: escuto" (SERRES, 1990, p. 174).

Para Nancy (2007; 2013a), o sonoro é da ordem de uma presença que chega, que penetra. Na escuta o tempo se faz espaço, se propaga, ressoa e reverbera. Escutar é adentrar em uma espacialidade na qual ao mesmo tempo sou penetrado. Por implicar uma experiência estésica do corpo, uma experiência rítmica que faz o corpo vibrar e estender-se ao tocar e ser tocado, há uma relação de si e fora de si. Um "sentir-se sentir" que faz do corpo uma singularidade plural de sentido, a força e a diferença que cada corpo é (NANCY, 2017). Estar à escuta é estar ao mesmo tempo em mim e no mundo. Em suas fronteiras, o audível e o inteligível ou o sonoro e o musical podem apenas tocarem-se em suas distinções, ou seja, são as suas diferenças que permitem a cada um tocar o outro.

$\mathrm{Na}$ escuta da música, o som e o sentido se misturam, ressoando um no outro ou um pelo outro, constituindo a singularidade sensível que conteria de modo mais ostensivo a condição sensível como tal: a partilha de um dentro/fora, divisão e participação, desconexão e contágio, dissonância e consonância. Escutar implica entrar nessa espacialidade, tempo que se abre, se retrai e se alarga ou se ramifica, envolve e coloca e se coloca em onda, se estira e se contrai. O som tendencialmente desaparece e o sentido tendencialmente pode se tornar som (NANCY, 2007; 2013a).

A acepção de sentido é entendida, com Nancy (2003, p.65), como "apresentação ou como vinda à presença", ou seja, como aquilo que tanto preexiste à determinada significação quanto a excede, pois "simplesmente, não há procedência do sentido: ele se apresenta" (NANCY, 2003, p. 66). Se a significação implica um sentido identificado, o sentido, talvez, "não resida mais que na vinda de uma significação possível" (NANCY, 2003, p. 11). 
Essa "vinda à presença”, em Nancy (2007; 2013a), não é postura de um corpo estar presente em um tempo e um espaço, não é um "em vista de" ou um "em face de". A escuta - como abertura à ordem do sonoro - é presença no sentido de uma "em presença de", um presente que é "um vir e um passar, um se estender e um penetrar. O som essencialmente provém e se dilata, ou se difere e se transfere" (NANCY, 2013a, p. 167). A escuta, por ser simultânea ao acontecimento sonoro, implica adentrar um espaço-tempo que me adentra. Estar à escuta significa tanto abertura de mim quanto ao redor de mim. É estar "ao mesmo tempo no fora e no dentro, estar aberto de fora e de dentro, portanto de um a outro, e de um no outro" (NANCY, 2013a, p. 167). Essa singularidade sensível, a qual vale também aos outros sentidos e modos de sentir justamente por constituírem um conjunto entrecruzado em sua complementaridade e incompatibilidade7, promove abertura aos modos lúdicos de estar em linguagem como desafio ao jogo de produzir sentidos sensíveis e sentidos sensatos (NANCY, 2007; 2013a) com outros na convivência mundana. Desde o nascimento.

O sentido inteligível, ao se enlaçar ao corpo em movimento e articular o sensível, permite que este se apresente, ou seja, “se pesaria e se sentiria junto ao som, às imagens, às diferentes cores, texturas e densidades do mundo. (...) produzindo uma diversidade de acessos sensíveis" (GHETTI, 2013, p. 149). Essa diversidade de "acessos sensíveis" diz respeito à complexa dinâmica diferenciada dos sentidos. Nessa diversidade, sublinha Nancy (2013a, p. 162), o par auditivo (ouvir e escutar) estabelece uma particularidade com o sentido na acepção intelectual ou inteligível da palavra, pois escutar (entendre em francês) também significa compreenders. Assim, há na inteligibilidade, em todo entendimento lógico (logos) - em todo discurso, em toda cadeia de sentido - um escutar que é também uma escuta e, talvez, seja "necessário que o sentido não se restrinja a fazer sentido (ou de ser logos), mas que além disso ressoe" (NANCY, 2013a, p. 163). Implica

\footnotetext{
7 Nancy $(2017$, p. 22) explicita a necessária análise diferenciada dos sentidos para que não se perca de vista que o dito para o sonoro vale também para os demais sentidos, bem como o sentido sensato. Essa diferenciação permite ao autor negar uma suposta arte no singular para afirmar a pluralidade das artes em Las Musas (NANCY, 2008) e em El arte hoy (NANCY, 2014).

8 Característica de certas línguas latinas na qual a palavra intendere é, em latim, "tender para".
} 
estar à escuta: música e docência na educação infantil

compreender que, se todos os sentidos participam da dimensão tátil, do tocar e ser tocado, cada um modula à sua maneira essa participação, pois a diferença das modulações é inerente à sensibilidade,

que não pode ser uma e geral. Se ela o fosse, ela teria apenas um "sensível" abstrato, um conceito de sensível. Mas em cada regime ela faz valer, simultaneamente, uma sensibilidade (visual, auditiva, etc) $e$ a pluralidade das sensibilidades, ou seja, o fato de que elas remetem umas às outras de forma diferenciada e inesgotável (NANCY, 2017, p. 22).

Estar à escuta exige compreender a pluralidade de sensibilidades que o corpo mobiliza e faz circular como anterioridade a qualquer significação, a qualquer distinção de lugar ou de função, como ressonância daquilo que no corpo vibra ao pôr-se em escuta. Essa singular experiência estésica convoca "o corpo a agir em linguagem no ato mesmo de atribuir valores e sentidos que nos colocam e nos enraízam no mundo, que nos fazem reconhecer as coisas no mundo" (RICHTER, 2016, p.99). Aqui, antes de ser palavra, língua, voz e significação, linguagem é

a extensão e a simultaneidade do "com" como maior potência de um corpo, sua propriedade de tocar a outro corpo (de tocar-se), que nada mais é que sua de-finição de corpo. Finaliza - cessa e se cumpre, com um mesmo gesto - onde é-com (NANCY, 2006, p. 108, grifos do autor).

A linguagem, nessa compreensão, não é instrumento de comunicação, mas a vitalidade como os corpos anunciam uns aos outros. Por ser a linguagem prolongamento do corpo, de ser o corpo "mensurador de todas as coisas" (MERLEAU-PONTY, 1999, p. 146); por ser essa experiência existencial inseparável da experiência de "viver-com", a linguagem não é instrumento de comunicação e a comunicação não é um instrumento para "ser". Por extensão, a ação educativa não se reduz à comunicação de informações a serem reconhecidas e acumuladas, mas experiência intransferível de apropriar-se de uma relação com o mundo.

A ação transfiguradora da pluralidade dos sentidos em experiência de linguagem, a qual simultaneamente nos ex-põe ao mundo e nele nos situa, diz respeito ao poético, àquilo ao que os antigos gregos empregavam o verbo poïein para dizer o vigor do agir temporalizado por linguagem e o substantivo poíesis para o sentido do agir (CASTRO, 2004). Convém destacar com Castro (2004, p. 55) 
que esse "agir" - por ser linguagem - não é o que o humano faz ou realiza, "mas o que constitui e realiza o humano". Supõe compreender que o poético implica "primeiramente ao que o fazer quer dizer: o que o fazer faz à linguagem quando a perfaz em seu ser, que é o acesso ao sentido. Quando dizer é fazer e quando fazer é dizer" (NANCY, 2013b, p. 421). O poético é assim linguagem em tensão de surgimento como disposição ao sentido sempre por fazer.

Somos o sentido inteiro. Sem reservas. A constituição do mundo é, em Nancy (2006, p. 19), justamente essa “explosão da presença na multiplicidade original de sua participação". Para o filósofo, a escuta é o gesto de tocar que pode estremecer e se fazer movimento, porque ex-posição ao mundo. Tocar o mundo para acolher a fruição de um corpo que no gesto poético pode desenhar o som. Escutar é tocar na simultaneidade de ser tocante e sentir-se tocado. O toque na filosofia, nas artes e na docência não é uma metáfora. Se trata sempre de realidade sensível que atrai e rejeita, é pulsão e repulsão, ritmo de fora e de dentro. É sempre um corpo-a-corpo com o mundo como ato que acompanha seu próprio excesso, sem fragmentações.

A escuta, por emergir da ação de tocar e ser tocado pelo mundo, é movimento, é produção e circulação de sentido. Como afirma Michel Serres (2004, p. 15), “o corpo em movimento federa os sentidos e os unifica nele". Mais, o corpo respira. E é ao mover-se que o corpo emerge aquém da linguagem. O gesto do corpo sensível tocar o mundo é experiência estésica fundamental do se-sentir, na qual cada sentido se toca ao sentir como modo ou registro sensível de expor um dos aspectos do "(se) tocar" (NANCY, 2007; 2013a).

A escuta, assim, remete à co-implicação entre corpo e mundo, à dimensão intercorporal de sentidos apreendidos na reciprocidade de gestos compartilhados. Lúdicos, sonoros, poéticos. Contornos expressivos de gestos e ações que ressignificam a docência com crianças ao ultrapassarem a redutora cisão entre sensível e inteligível, sonoro e musical, corpo e razão, afinado e desafinado, ensino com partitura e sem partitura. Ao negarmos tais oposições simplificadoras na ação educativa afirmamos que a ação de estar à escuta na música e na docência com 
estar à escuta: música e docência na educação infantil

bebês e crianças pequenas implica ação do corpo no mundo na qual tensão, atenção e intenção ressoam a materialidade sonora da coexistência.

\section{o som do sentido}

O som não tem lugar, mas ocupa o espaço. A música toca, o ruído assedia, o rumor envolve o corpo todo. Quem foge de uma cena abaixando as pálpebras, cobrindo os olhos com as mãos, ou virando as costas, não consegue se livrar de um ruído, de um clamor. Nenhuma divisória o detém. Qualquer matéria, a rigor, vibra e conduz o som, sobretudo a carne. O modo como nos colocamos em "escuta" em ressonância - ao eco das coisas em nós: como as lembramos, as pensamos e as sonhamos formam um único tecido: "escuta bem, contudo. Não as minhas palavras, mas o tumulto que se eleva em teu corpo quando me escutas" (BACHELARD, 1989, p.186).

O corpo vive a materialidade do gesto sonoro pela possibilidade de sentido emergir da disponibilidade de abertura à ressonância, ao fato de que "aquele que emite um som escuta [entend] o som que ele emite" (NANCY, 2013a, p. 168). A escuta, como o som do sentido, é vigor da ação de tocar-se na presença do toque. Não é discurso sobre o mundo, mas ação de tocar o mundo. Aqui, o sentido é sua própria instauração e circulação.

Se a escuta é o som do sentido, o que seria o som? Por princípio o som é um sinal, uma onda invisível e impalpável oscilante e recorrente que retorna por diferentes períodos. Ele nunca está só. Sendo emergência “de uma sequência de impulsões e repousos, e de quedas cíclicas desses impulsos, seguida de sua reiteração" (WISNIK, 1989), o som contém sempre a partida e a contrapartida do movimento, ou melhor, o movimento e a pausa. Os corpos vibram e, essa vibração transmite uma propagação ondulatória que ocorre no tempo em determinada periodicidade, repetida com certa frequência, num campo sincrônico. Não implica somente, para o corpo sonoro, emitir um som mas "sempre e ao mesmo tempo é o corpo que ressoa e meu corpo de ouvinte onde isso ressoa, ou ainda, que nele ressoa" (NANCY, 2013a, p. 164). 
Wisnik (1989) contribui para compreender que o som, como onda sonora, obedece a um pulso, seguindo o princípio corporal da pulsação. Assim, o ritmo é o tempo do movimento, ou o tempo de um tempo que pulsa no presente que o apresenta. Duração, altura, timbre, intensidade, densidade, vibram juntas, sem separações em suas ressonâncias, antes como tempo próprio ao acontecimento. Ao afirmar que “o jogo entre som e ruído constitui a música”, Wisnik (1989, p.30) desloca o modelo idealizado de música e nos mostra o intenso esforço que consiste converter o ruído em som ordenado. Como o som do mundo é ruído, produzir (poíesis ou poético)9 uma ordenação dessas frequências irregulares e caóticas tem sido o grande esforço histórico da música. Expressão de poder, crença e liberdade constituído pelo jogo sonoro que silencia os ruídos ao interpretá-los e conduzi-los a soar como sentido provocado pela ressonância que produziram nos corpos, isto é, como resposta a uma convocação de sentido.

A aproximação às ideias de Nancy e de Wisnik contribuem para interrogar o encontro entre música e docência na educação infantil a partir do som e das relações entre sentido sensível e sentido inteligível inerentes aos verbos escutar e ouvir. Para Nancy (2007; 2013a), o verbo ouvir designa compreender previamente o som a partir de uma convenção ou predeterminação, enquanto escutar designa o gesto de abertura ou acesso ao sentido que ressoa. Nesse contexto, estar à escuta, não é permanecer estático em silêncio para apreender uma representação da linguagem, para repetir uma convenção, ou mesmo para manter uma afinação mas, como afirma Wisnik (1989), deixar o som fazer sentido como música. A escuta musical emerge então como a música mesma. A música, antes de tudo, "se escuta, seja escrita ou não e, quando o é, desde sua composição até a sua execução. Se escuta de acordo com as diferentes flexões possíveis da expressão: é feita para

\footnotetext{
9 Conforme a história do termo poíesis, a dimensão poética nomeia um conflito - ou uma disputa pela compreensão do significado de "produção". Uma divergência histórica entre a sensibilidade de produzir algo e sua efetuação técnica. Porém, como afirma Nancy (2008, p. 45, grifos do autor), "A produção, no singular e em termos absolutos, não é outra coisa que a produção do sentido". A questão histórica do dissenso em torno do poético é o duplo sentido de "sentido", o sentido sensível e o sentido inteligível. Dupla interrogação em torno da simultânea interioridade e exterioridade das artes na qual o sentido expõe sua condição de produção como reunião do sensível e do inteligível.
} 
estar à escuta: música e docência na educação infantil

ser escutada, mas é antes, em si, escuta de si" (NANCY, 2007, p. 55). Uma escuta disposta pela

profundidade de uma caixa de ressonância que não é outra que o corpo de um extremo a outro - uma relação com o sentido, uma tensão até ele: mas até ele em completa anterioridade à significação, sentido em estado nascente, em um estado de remissão a ele no qual não está dado o fim desta última (o conceito, a ideia, a informação) e, portanto, em um estado de remissão sem fim, como um eco [...] (NANCY, 2007, p. 55).

Tal ação parte de um corpo que pode brincar com a sonoridade do mundo, ou melhor, que vive a poética do barulhar (LINO, 2008). Aqui, a poética define o acesso singular ao sentido pela disponibilidade à ressonância e o barulhar a potência de jogar e brincar com sons. Ao destacarmos a ação de "barulhar" como a música da infância consideramos que as crianças fazem barulho pela estesia de escutar o mundo. Desde muito cedo as crianças compreendem que a música é um jogo sonoro de regras em movimento contínuo (LINO, 2008). Ao brincar com sons, elas se entregam ao desejo e ao risco de ressoar sentidos na imprevisibilidade e indeterminação característicos da ludicidade, sem se importar com as formas comunicadas ou compartilhadas. Aqui não há hierarquia nem fragmentações. $\mathrm{O}$ som, o ruído, o silêncio e as músicas do entorno cultural das crianças coexistem na rede de singularidades por elas constituídas na pluralidade da convivência com outros.

Delalande (1995) afirma que as crianças têm apetite pelo ruído. Isso não significa que primeiro há o sonoro definido como som e ruído, para depois chegar ao musical como ordenação sonora do ruído orquestrada pelo humano. A música se expõe na complexidade e pluralidade de enfrentar o risco de suas ressonâncias para vibrar simultaneamente livres experimentações, coerências musicais instituídas pelo discurso sonoro em distintas culturas e inventariar modos de compor (LINO, 2008). As crianças se entregam ao puro deleite de estarem à escuta na ação lúdica de barulhar. Ao brincarem com sons, deglutem influências aparentemente contraditórias e jogam com o sonoro e o musical.

O caráter lúdico e participativo da ação de barulhar das crianças remete ao apetite pelo mundo sonoro. Ao brincarem com sons jogam com a intimidade do gesto de escuta como estremecimento do corpo que suscita o pensamento pela 
sensibilidade ao mundo que abre todos os sentidos ao infinito (NANCY, 2006). A ação de barulhar das crianças emerge pela entrega à escuta do mundo, sem se preocuparem com a ordenação sonora do mesmo, ou a gramática a cumprir. A docência na educação infantil pode compreender com a música que o som não pode ser tocado diretamente, mas nos toca com enorme precisão. Seu poder invasivo, incontrolável em sua emergência sonora - envolvente, apaixonante, aterrorizante, exige um tempo, uma pulsação e um ritmo não repetitivo, fora do metrônomo das rotinas escolares. Reivindica um espaço para que a altura possa acontecer, ou seja, requer tempos e espaços sonoros disponíveis para parcerias, para juntar e separar, para entrar em sintonia, para compor.

A música só pode ser alimentada pela força da música, ou melhor, pela materialidade sonora da coexistência, pelo tocar o mundo que é ruído, barulhando, e não por prévia determinação dos começos. O ato de barulhar, improviso do corpo que decide iniciar o gesto de estar à escuta, é “composição em movimento" (ALONSO, 2014). Dos poros, dos ouvidos, de um corpo que toca o mundo para ressoar concomitantemente sensível e inteligível, num movimento constante que não se completa ou finaliza produzindo uma informação ou uma significação (porque assim, deixaria de fazer sentido), mas que implica tanto uma "partilha" quanto uma "partição".

O termo francês "partage" é concebido por Nancy (2016) tanto no sentido de "partilha" como no de "partição" - tanto compartilhar quanto repartir, separar. Somente um corpo separado pode tocar, pois tocar começa "quando dois corpos se distanciam e se distinguem um do outro" (NANCY, 2017, p. 16). A escuta é sonora porque sendo gesto que toca o mundo e por ele é tocado, narra a potência de partida como partitura. Nancy (2007; 2013a) destaca o sentido musical da partitura, escrita no pentagrama para registrar tanto os momentos da melodia como também a repartição das diferentes vozes ou distintos instrumentos em uma orquestra. Nessa concepção, música emerge como dimensão do corpo sonoro que não necessita ser traduzida nem transferida, na qual o corpo é o princípio e o fim, a partitura escrevendo-se e soando. O paradoxo está na unidade do múltiplo. 
estar à escuta: música e docência na educação infantil

\section{estar à escuta na docência com crianças}

A música é viva! Tudo que é vivo se movimenta. Transforma-se. O mundo sonoro se recria e se renova continuamente, desafiando-nos a produzir sentidos e perceber outros mundos no mundo em que estamos inseridos. Nesse sentido, podemos afirmar que a condição de estar à escuta é habitar os tempos e os espaços sonoros do mundo. Com Bárcena (2012) podemos interrogar: como habitamos a educação? Como habitamos uma casa? Para o filósofo, habitamos a educação com o corpo e o gesto produtor de narrativas que ressoam sentidos e incorporam provocações (BARCENA, 2012, p.67). Assim, o que implica na educação infantil habitar tempos e espaços sonoros? Uma casa vazia é tão inabitável quanto uma casa cheia de coisas (BARCENA, 2012).

A presença da música na educação infantil permite oferecer tempos e espaços sonoros propositivos para que as crianças possam dar estado de existência às sonoridades do mundo. Nessa experiência organizada intencionalmente pelos professores, as crianças podem experimentar a duração sempre em movimento: quando termina, recomeça outra experiência. Como os índios pesquisados por Egberto Gismonti (FREGTMAN, 1991) o fizeram entender. Depois de uma sessão de improvisação de toda a tribo, o compositor solicita que se repitam alguns trechos sonoros que considerou interessantes para a gravação. O cacique comenta: "música igual àquela não se fará jamais; amanhã conversaremos com outras almas, faremos outra música" (FREGTMAN, 1991, p.54). Aqui, os tempos e espaços sonoros habitados pelas crianças têm a escuta como fundamento estruturante da proposição pedagógica. É porque a escuta emerge como integradora de diferentes jogos sonoros que podem fluir na rotina escolar. Assim, perseguir formigas no pátio, manipular objetos do cotidiano, explorar os corredores vazios da escola podem transformar os elementos sonoros do discurso musical e suas conexões hierárquicas, que incluem uma babel de modos de estar em linguagem (LINO, 2008). 
Viver a escuta ao habitar os tempos e espaços sonoros mundanos é para as crianças um processo de transbordamento de afeto e alegria conquistado sempre que podem soar ou encontrar provisoriamente disponibilidade à indeterminação. No ato de barulhar, não há ensaio articulado anteriormente como condição da fruição sonora (as crianças não ensaiam uma nota, uma passagem, um jeito de produzir o som); as crianças se expõem, explorando e tateando as materialidades dispostas em suas resistências. Nesse caso, podem perseguir reiteradamente uma sonoridade, entregando-se ou contrapondo-se a desafiar as leis da física a partir do produto audível conquistado ou jogando com a possibilidade de incitá-lo (LINO, 2008, p.131).

No entanto, nosso ouvido continua procurando aquilo que já conhecemos. Isso porque somos todas as músicas que ouvimos. Porém, temos culturalmente dedicado extenso tempo para a visualidade em detrimento da escuta. Fomos deixando de escutar.

Deixamos de escutar as vozes que são diferentes, os silêncios que são diversos. E deixamos de escutar não porque nos rodeasse o silêncio. Ficamos surdos pelo excesso de palavras, ficamos autistas pelo excesso de informação. A natureza converteu-se em retórica, num emblema, num anuncio de televisão. Falamos dela, não a vivemos (COUTO, 2005, p. 123).

Afinal, para que serve aprender a estar à escuta? O maior perigo está sempre na inutilidade. Esse é nosso problema, afirma Skliar (2012, p. 17). Interrompemos o tempo das crianças ao perguntarmos "para que serve". Porém, "não existe outra resposta que 'para nada, para isso mesmo, para isso mesmo que ocorre agora, agora mesmo. Fora daqui não tem sentido, não existe, não está, não é" (SKLIAR, 2012, p. 17). A sabedoria das crianças, destaca Hoyuelos (2008, p. 11) está justamente em "abraçar a oportunidade do momento". Que tempos e espaços sonoros estamos hoje oferecendo à ressonância das crianças pequenas? Como vencer a inércia do fast food musical que vem comodamente sentado no colo da mídia e do lucro?

Quando o bebê nasce, ele não tem língua. Mas tem a capacidade de estar em todas as sonoridades e produzir todos os sotaques do mundo. Por isso, bebês no mundo inteiro balbuciam, gorgojeiam, riem e choram com padrões sonoros 
estar à escuta: música e docência na educação infantil

muito semelhantes. Ao participarem da coexistência vão gradualmente se apropriando dos ritmos, dos tempos e espaços mundanos, apreendendo as sonoridades e as músicas disponíveis à escuta e experimentação lúdica. Em pouco tempo se apropriam da língua e a fazem sua pela escuta do que o ouvido aprendeu a escutar. Nessa apropriação, os bebês compreendem que diferentes expressões vocais assumem distintos sentidos e significados. Falar e cantar, gritar e chorar são vocalizações que guardam diferenças enormes na ressonância de seu corpo.

Ressoar é viver o inefável e o inesgotável do gesto de estar à escuta. Somos sonoridade em cada ato. Aqui o silêncio não se opõe ao som. O silêncio é duração e a duração é tempo de estar à escuta e experimentar "modos de ação". Nascemos chorando. Crescemos brincando - barulhando - intensamente com os sons. Morremos dando o último suspiro. Nessa compreensão, a docência na educação infantil convoca a responsabilidade de viver, como adultos, a escuta desde sua ressonância e imprevisibilidade para acompanhar o "barulhar" das crianças em seus percursos sonoros. Experimentar a vibração da escuta como o tempo e o espaço de pensar a música na docência com bebês e crianças pequenas significa empreender a ressonância como o som do sentido, experiência de constituir-se corpo sonoro.

O desafio da docência na educação infantil está em enfrentar a proximidade perturbadora entre as artes ou seus distintos modos de acontecer, em pedagogicamente acolher a pluralidade das artes que emerge da singularidade do corpo que sente, do corpo que "é uma unidade plural de sentido" (NANCY, 2008, p. 142). Se a singularidade plural das artes permite a aproximação entre distintos modos de ressonância no corpo sensível também permite a distanciação entre eles ao estabelecer intraduzíveis modos de estar em linguagem. O que está em jogo é a diferença dos sentidos em seus modos de presença, ou seja, cada modo poético de estar em linguagem - só apreensível em seu silêncio próprio - expõe a singularidade das artes como abertura de mundo que, por dizer respeito a um modo de ser no mundo, é sempre pluralidade de mundos (NANCY, 2008). Assim, 
não tratamos de buscar uma "definição" ou uma "determinação" da arte, antes temos como pretensão destacar a relevância educacional de não desconsiderar essa diversidade ao promover o encontro entre música e educação infantil.

Provocar a imaginação e desafiar sentidos sensíveis e sensatos das crianças é também provocar e desafiar a docência à escuta das possibilidades de compartilhar sentidos na ação educativa. Implica juntos ensaiarem e explorarem ressonâncias, transformarem sonoridades em sentidos que signifiquem a convivência na educação infantil. Supõe a intencionalidade pedagógica de considerar que a escuta não quer identificar, classificar e/ou reconhecer a tradição musical instituída. Escutar a escuta - estar à escuta - demanda o encontro, o cuidado e a acolhida aos tempos e espaços intersubjetivos como experiência lúdica de singularidades plurais constituídas no mundo comum. Escutar é uma das tantas experiências estésicas no cotidiano da educação infantil que temos pretendido perseguir para destacar que o sentir, nossa sensibilidade, é o elo de integração vital com o mundo que o torna familiar para nós como condição de habitá-lo coexistindo.

Nessa condição vital, a experiência sensível, aquela que se apreende com os sentidos, não é da ordem do instrumental, pois os sentidos não são "condutores" instrumentos ou meios, não podem ser definidos como efeitos de um estímulo exterior, antes é da dimensão estésica ao envolverem sensações oferecidas à potência sensível de todo o corpo movimentar-se no e com o mundo; uma potência ubíqua ou "que co-nasce em um certo meio de existência ou se sincroniza com ele" (MERLEAU-PONTY, 1999, p. 285). Por isso, para Merleau-Ponty (1999), a experiência sensível é tão vital como a procriação, a respiração ou o crescimento. Sentir (aisthesis),

é sempre um ressentir, ou seja, um se-sentir-sentir: ou ainda, caso se prefira, o sentir é sujeito, ou ele não sente. Mas é porventura no registro sonoro que essa estrutura reflexiva se expõe de modo mais manifesto, e em todo caso se propõe como estrutura aberta, espaçada e espaçante (caixa de ressonância, espaço acústico, afastamento de um reenvio), ao mesmo tempo que como cruzamento, mescla, recobrimento no reenvio do sensível ao sensato assim como aos outros sentidos (NANCY, 2013a, p. 164). 
estar à escuta: música e docência na educação infantil

Essa experiência de se-sentir-sentir configura um estado diferenciado de atenção, uma atenção para a inteligibilidade das coisas pela íntima relação entre corpo sensível e experiência do mundo que a "a cada instante se faz em nós" (MERLEAU-PONTY, 1999, p. 440). O corpo sensível é fonte primeira dos sentidos que vamos constituindo com o mundo e imantando-o com nossas interpretações, produzindo sentidos encarnados a partir dos sentidos que o mundo oferece.

Talvez, antes de priorizar metodologias produtivas ou conhecimentos verificáveis na ação educativa com bebês e crianças pequenas tenhamos que reter e explorar o que em nós permanece como ritmo vital. Uma busca pela anima1o ou por aquilo que não é passível de ser visualizado e quantificado, apenas sentido pelo que nos toca e atravessa todos os sentidos, aquilo que exige inflexão e incorporação por vibração: a partição e a partilha do mundo, a nossa existência e muito precisamente o fato de esta existência é em comum, que ela é um "ser/estar-com" ou com-partição. Partição e partilha das vozes, dos signos, dos gestos, das formas, do sentido sentido e do sentido sensato que nos situam sendouns-com-os-outros na coexistência mundana. Implica à docência na Educação Infantil assumir pedagogicamente que o que nos relaciona uns com os outros, antes de conhecimentos ou informações, é a abertura sensível ao som do sentido promovido pelo gesto de estar à escuta, ao modo como escutamos e tatuamos no corpo a coexistência.

\section{referências}

ALONSO, Chefa. Enseñanza y aprendizaje de la improvisación libre. Propuestas y reflexiones. Editorial Alpuerto: Madrid, 2014.

BACHELARD, Gaston. A poética do espaço. São Paulo: Martins Fontes, 1989.

BÁRCENA, Fernando. El aprendiz eterno: filosofia, educación y el arte de vivir. Madrid: Minõ y Davila, 2012.

BORNHEIM, Gerd. As metamorfoses do olhar. In: NOVAES, Adauto (org). O olhar. São Paulo: Companhia das Letras, 1988, p. 89 - 93.

\footnotetext{
10 Não se trata de uma metáfora, mas de uma realidade vibratória. "Quando uma alma estremece, ela estremece bela e lindamente, assim como se pode dizer de uma água em grande agitação. O que se costuma chamar de 'alma' também não é nada senão o despertar e a recepção - os dois juntos da moção/emoção. A alma é o corpo tocado, vibrante, receptivo e reativo" (NANCY, 2017, p. 2627).
} 
CASTRO, Manuel A. de. Poiesis, sujeito e metafísica. In: CASTRO, Manuel A. de (org.) A construção poética do real. Rio de Janeiro: 7 Letras, 2004, p.13-82.

CERF, Juliette. Jean-Luc Nancy, penseur du corps, des sens et des arts. Telerama, O7/201. Entretien publié le 14/07/2012. Disponível em: $<$ https:// www.telerama.fr/idees/jean-luc-nancy-penseur-du-corps-des-sens-etdes-arts,84213.php> Acesso em 12 nov. 2018.

COUTO, Mia. Pensatempos: textos de opinião. Lisboa: Editorial Caminhos, 2005.

DELALANDE, François. La música es um juego de niños. Buenos Aires: Ricordi Americana, 1995.

FREGTMAN, Carlos Daniel. Música transpessoal. Uma cartografia holística da arte, da ciência e do misticismo. São Paulo, SP: Cultrix, 1991.

GHETTI, Paola. Uma filosofia que seja o estremecer de um som: sobre o sentido em JeanLuc Nancy. outra travessia, Florianópolis, n. 15, p. 147-155, out. 2013. Disponível em: $\quad$ <https://periodicos.ufsc.br/index.php/Outra/article/view/21768552.2013n15p147> Acesso em: 06 ago. 2017.

HELLER, Alberto Andrés. John Cage e a poética do silêncio. Florianópolis: Letras Contemporâneas, 2011.

HOYUELOS, Alfredo. Los tiempos de la infancia. Temps per Creixer. Universidadad Autonoma de Barcelona, Barcelona, 2008. p..15-30.

LINO, Dulcimarta Lemos. Barulhar: a escuta sensível da música nas culturas da infância. Porto Alegre, 2008. Tese (Doutorado em Educação) - UFRGS, Universidade Federal do Rio Grande do Sul.

MALBA (Argentina). Yoko Ono Dream Come Tru. Catálogo de la exposición Dream Come Tru de la artista Yoko Ono. 24 Junio - 30 Octubre 2016. Curadores de la muestra Gunnar B. Kvaran y Agustin Pérez Rubio, Buenos Aires, Junio 2016. Disponível em: <https://malba.org.ar/evento/yoko-ono-dream-come-true/> Acesso em 14 mar. 2019.

MERLEAU-PONTY, Maurice. Fenomenologia da percepção. São Paulo: Martins Fontes, 1999.

NANCY, Jean-Luc. El olvido de la filosofía. Madrid: Arena Libros, 2003.

NANCY, Jean-Luc. Ser singular plural. Madrid: Arena Libros, 2006.

NANCY, Jean-Luc. A la escucha. Buenos Aires: Amorrortu, 2007.

NANCY, Jean-Luc. Las Musas. Buenos Aires: Amorrortu, 2008.

NANCY, Jean-Luc. O peso de um pensamento, a aproximação. Coimbra, Portugal: Editorial Palimage, Terra Ocre Edições, 2011.

NANCY, Jean-Luc. À escuta (parte I). outra travessia, Florianópolis, n. 15, p. 159-172, out. 2013a.

em: $<$ https:// periodicos.ufsc.br/index.php/Outra/article/view/21768552.2013n15p159/25525> Acesso em: 03 jan. 2018.

NANCY, Jean-Luc. Fazer, a poesia. ALEA: Rio de Janeiro. Jul-dez 2013b, vol 15/2, p. 414422. Disponível em: <http://www.scielo.br/pdf/alea/v15n2/10.pdf> Acesso em 10 jun. 2019.

NANCY, Jean-Luc. El arte hoy. Prólogo de Daniel Alvaro. Ciudad Autónoma de Buenos Aires: Prometeo Libros, 2014.

NANCY, Jean-Luc. Arquivida. Do senciente e do sentido. São Paulo: Iluminuras, 2017.

RICHTER, Sandra R.S. Educação, arte e infância: tensões filosóficas em torno do fenômeno poético. Revista Crítica Educativa, v. 2, n. 2, 2016, p. 90-106. Disponível em:

<http:/ / ww.criticaeducativa.ufscar.br/index.php/criticaeducativa/article/view/ 99> Acesso em: 12 out. 2017. 
estar à escuta: música e docência na educação infantil

RINALDI, Carla. Diálogos com Reggio Emilia: escutar, investigar, aprender. São Paulo: Paz e Terra, 2012.

SERRES, Michel. Hermes: uma filosofia das ciências. Rio de janeiro: Graal, 1990

SERRES, Michel. Variações sobre o corpo. Rio de Janeiro: Bertrand Brasil, 2004.

SKLIAR, Carlos. As interrupções no corpo, a atenção, a ficção e a linguagem da infância. In: XAVIER, Ingrid; KOHAN, Walter. Filosofar: aprender e ensinar. Belo Horizonte: Autêntica, 2012, p. 15-24.

WISNIK, José Miguel. O som e o sentido. Uma outra história das músicas. São Paulo, Companhia das Letras, 1989.

recebido em: 12.07.2019

aprovado em: 18.09.2019 